\title{
HACIA UNA CARACTERIZACIÓN FILOLÓGICA DE LOS DOZE TRABAJOS DE HÉRCULES DE DON ENRIQUE DE VILLENA*
}

\author{
Santiago Vicente Llavata \\ llavata@uv.es \\ Universidad de Valencia
}

\section{INTRODUCCIÓN}

Desde que la profesora M. Morreale editara y estudiara Los doze trabajos de Hércules en el ecuador del siglo pasado ${ }^{1}$, los estudios sobre esta primera creación literaria de don Enrique de Villena no se han prodigado en exceso. Hay que esperar hasta la década de los años ochenta para asistir a un hito fundamental en el estudio de esta obra y de su autor. En efecto, la aportación filológica del profesor P. Cátedra ${ }^{2}$ ha alumbrado de forma decisiva el conocimiento del universo villenesco con la publicación de sus obras completas ${ }^{3}$, con la descripción de la transmisión textual de su producción artística ${ }^{4}$ o con los numerosos estudios literarios centrados en aspectos como el rastreo de sus obras perdidas (con una atención especial en la obra escrita en catalán) o en la recepción de su obra en otros espacios peninsulares 5 .

\footnotetext{
* Este artículo se inscribe en el proyecto «Historia e historiografía de la lengua castellana en su diacronía contrastiva» (HISLECDIAC) con referencia FFI2017-83688-P, financiado por la Agencia Estatal de Investigación (AEI) y el Fondo Europeo de Desarrollo Regional (FEDER) y gestionado por la Universitat de València a través del Departamento de Filología Española por la Dra. M. ${ }^{a}$ Teresa Echenique Elizondo y por la Dra. M. ${ }^{a}$ José Martínez Alcalde en calidad de investigadoras principales. El proyecto forma parte del Programa Estatal de Fomento de la Investigación Científica y Técnica de Excelencia, Subprograma Estatal de Generación de Conocimiento.

${ }^{1}$ Margherita Morreale, «Un ensayo medieval de exégesis mitológica: Los doze trabajos de Hércules de Enrique de Villena», Revista de Literatura, 5 (1954), pp. 21-34; Enrique de Villena, Los doze trabajos de Hércules, Margherita Morreale (ed.), Madrid, Real Academia Española, 1958. Trabajos que pueden considerarse ya clásicos de la Filología española. Anteriormente a este hito, se localiza la biografía de Emilio Cotarelo y Mori, Don Enrique de Villena. Su vida y obras, Madrid, Est. tipográfico de sucesores de Rivadeneyra, 1896.

${ }^{2}$ Pedro M. Cátedra, Para el estudio de la biografia y la obra de Enrique de Villena, 9 vols., Bellaterra (Barcelona), Universitat Autònoma de Barcelona, 1981.

${ }^{3}$ Enrique de Villena, Obras completas, Pedro M. Cátedra (ed.), Madrid, Turner, 1994-2000.

${ }^{4}$ Pedro M. Cátedra, «Enrique de Villena», en Carlos Alvar Ezquerra y José Manuel Lucía Megías (eds.), Diccionario filológico de literatura medieval española. Textos y transmisión, Madrid, Castalia, 2002, pp. 454-467.

${ }^{5}$ Pedro M. Cátedra, «Algunas obras perdidas de Enrique de Villena con consideraciones sobre su obra y su biblioteca», El Crotalón: Anuario de Filología Española, 2 (1985), pp. 5375; Pedro M. Cátedra, «Sobre la obra catalana de Enrique de Villena», en Luisa López Grijera y Agustín Redondo (eds.), Homenaje a Eugenio Asensio, Madrid, Gredos, 1989, pp. 127-140; Pedro M. Cátedra, «Los Doze trabajos de Hércules en el Tirant (Lecturas de la obra de Villena
} 
En cuanto al análisis propiamente lingüístico, junto con el estudio de Morreale $^{6}$, contamos con un trabajo de Ridruejo ${ }^{7}$, en el que aborda las transferencias morfológicas y sintácticas en la prosa de Villena.

Sin embargo, si proyectamos nuestra mirada más allá del estudio concreto de esta obra, podremos constatar que la hispanística se ha interesado decididamente por la obra artística de este noble castellano a caballo, por lazos de sangre, entre la Corona de Castilla y la Corona de Aragón ${ }^{8}$. En una visión general del estudio de su obra ${ }^{9}$, se ha de destacar la enorme labor realizada en el campo de la crítica textual, pues hoy podemos acceder al conjunto de sus creaciones literarias a través de ediciones críticas de fiabilidad contrastada ${ }^{10}$, lo que permite estudiarlas desde un enfoque filológico integrador ${ }^{11}$, representativo de la mejor tradición de la Filología española.

Con todo, a pesar de que en las últimas cuatro décadas se ha avanzado extraordinariamente en la descripción codicológica y literaria del conjunto de sus obras, así como en aspectos fundamentales en el estudio lingüístico, la obra literaria de don Enrique de Villena merece, en nuestra opinión, un estudio filológico integral ${ }^{12}$, en el que se trace una caracterización global de su estilo en dos direcciones: por una parte, en la descripción sistemática de las innovaciones que Villena introdujo en el discurso literario de su época y, por otra, en

en Castilla y Aragón», en Actes del Symposion Tirant lo Blanc, Barcelona, Quaderns Crema, 1993, pp. 171-205.

${ }^{6}$ Margherita Morreale, Los doze trabajos..., ed. cit., pp. LXI-LXII.

${ }^{7}$ Emilio Ridruejo Alonso, «Tres catalanismos (y aragonesismos) sintácticos en "Los doze trabajos de Hércules" del Marqués de Villena», Archivo de Filología Aragonesa, 34-35 (1984), pp. 273-290.

${ }^{8}$ Nieto de Enrique II de Castilla por parte de madre y bisnieto de Pedro el Ceremonioso de Aragón por parte de padre, don Enrique de Villena pasó su infancia en la corte ducal de Gandía, regida por su abuelo don Alfonso de Aragón, primer marqués de Villena y Condestable de Castilla. En ella, tuvo contacto directo con la familia March, pero también con figuras literarias de primer orden en el ámbito cultural de la Corona de Aragón, como Francesc Eiximenis o Antoni Canals. Su estancia prolongada en la corte ducal de Gandía le proporcionó también la posibilidad de estar presente en algunos de los actos más significativos de la corte real barcelonesa de Juan I y, posteriormente, de Martín el Humano.

${ }^{9}$ Para una visión sobre su vida y obra, véase Pedro M. Cátedra, Obras..., ed. cit., pp. XI-XXXI.

${ }^{10}$ En Pedro M. Cátedra, «Enrique de...», op. cit., pp. 465-466, se puede consultar el conjunto de ediciones.

${ }^{11}$ Junto con esta magna aportación en la labor de edición de textos, disponemos también de importantes estudios lingüísticos (además de excelentes ediciones) sobre algunas de sus obras literarias señeras: José Antonio Pascual Rodríguez, La traducción de la «Divina Commedia» atribuida a D. Enrique de Villena. Estudio y edición del Infierno, Salamanca, Universidad de Salamanca, 1974 y Ramón Santiago Lacuesta, La primera versión castellana de "La Eneida" de Virgilio, Madrid, Real Academia Española, 1979; Rolf Eberenz, «La catalanitat "subjacent" de 1'Arte Cisoria' d'Enric de Villena», en Josep Massot (ed.), Miscel-lània Germà Colón, 4, Barcelona, Abadia de Montserrat, 1995, pp. 95-106; Juan Gil, «Latinismos sintácticos en la traducción de la Eneida de don Enrique de Villena», Boletín de la Real Academia Española, tomo XCII, cuaderno CCCVI (2012), pp. 179-211.

${ }^{12}$ En la línea de los magistrales estudios de conjunto de Rosa María Lida de Malkiel, Juan de Mena, poeta del prerrenacimiento español [1950], México, El Colegio de México, 1984 y de Rafael Lapesa, La obra literaria del marqués de Santillana, Madrid, Ínsula, 1957. 
el registro de las continuidades y discontinuidades de esas formas inéditas en los escritores de las generaciones siguientes, con una atención especial en la obra literaria de don Íñigo López de Mendoza ${ }^{13}$.

Partiendo, pues, de esta constatación ${ }^{14}$, el objetivo fundamental de este artículo se basa en sintetizar la descripción referida al estilo literario villenesco, al tiempo que pretende ofrecer un conjunto de posibilidades de estudio en torno a la lengua literaria de este autor. Para ello, ofreceremos una breve descripción literaria sobre Los doze trabajos de Hércules como antesala a su análisis estilístico. Seguidamente, se expondrán los rasgos de estilo más relevantes de esta obra, así como las posibilidades de estudio a que aludíamos, con el fin de proyectarlas hacia objetivos de mayor alcance en el marco de la investigación filológica. Por último, en las consideraciones finales trataremos de ofrecer una caracterización global en torno a esta creación artística y a su autor.

\section{BREVE DESCRIPCIÓN LITERARIA DE LOS DOZE TRABAJOS DE HÉRCULES}

La primera creación artística que conocemos de don Enrique de Villena, Los dotze treballs d'Hèrcules ${ }^{15}$, escrita originalmente en catalán durante la primavera de 1417 en la ciudad de Valencia, constituye el primer ejercicio literario de interpretación mitológica del prerrenacimiento hispánico ${ }^{16}$, al tiempo que se erige como uno de los testimonios romances más antiguos del tópico de las armas y las letras. Pocos meses después, en septiembre de ese mismo año, Villena autotraduce a la lengua castellana el texto en catalán. La obra se inicia con una carta dirigida a su destinatario, el caballero mosén Pero Pardo, hombre influyente y cercano al rey Alfonso V el Magnánimo, en la que expresa en estos términos su finalidad principal ${ }^{17}$ :

Así será espejo actual a los gloriosos cavalleros en armada cavallería, moviendo el coraçón de aquéllos en non dubdar los ásperos fechos de las armas e emprender grandes e honrados partidos, enderesçándose a sostener el bien común, por cuya razón cavallería fue fallada ${ }^{18}$.

${ }^{13}$ Para una visión sobre el conjunto de su obra literaria, véase el estudio fundamental de Rafael Lapesa, «La obra literaria...», op. cit., así como los estudios de las ediciones críticas de Íñigo López de Mendoza, Poesías completas, Miguel Ángel Pérez Priego (ed.), Madrid, Alhambra, 1983-1991; Íñigo López de Mendoza, Poesías completas, Ángel Gómez Moreno y Maxim. P. A. M. Kerkhof (eds.), Madrid, Castalia, 2003.

${ }^{14}$ No será necesario insistir en la idea de que este estudio filológico integral solo será posible con la suma de muchos trabajos parciales que atiendan a los diferentes aspectos del estilo en cada una de sus obras.

${ }^{15}$ Existe una edición antigua del original en catalán $\left(4^{\circ}, 54\right.$ folios, $158 \times 109 \mathrm{~mm}$, impreso por Cofman el 30 de agosto de 1514 en Valencia), propiedad de un particular, por lo que no es posible acceder a ella.

${ }^{16}$ Margherita Morreale, Los doze trabajos..., op. cit. e Id., «Un ensayo medieval...», art. cit.

${ }^{17}$ Utilizamos la edición crítica de Pedro M. Cátedra, Obras..., ed. cit., para las citas textuales.

${ }^{18}$ Pedro M. Cátedra, Obras..., ed. cit., p. 6. 
En la introducción, Villena explica con detalle la disposición en cuatro secciones temáticas de cada uno de los doce trabajos evocados: en la primera sección titulada Historia, el autor narra los hechos tal como los historiadores y poetas antiguos la han transmitido. En una segunda sección titulada Alegoría, se centra en asignar a cada personaje o lugar una interpretación alegórica. En la tercera sección titulada Verdad, ofrece la versión "histórica" de los hechos tal y como supuestamente sucedieron. Finalmente, la cuarta sección -Aplicación-representa el esfuerzo de Villena por convertir en provechosas las enseñanzas de la Antigüedad clásica, en el sentido de asignar una actitud cívica orientada al bien común a cada uno de los estados ${ }^{19}$.

La obra se cierra con una conclusión, en la que hace referencia de nuevo a su estructura, así como a justificar su extensión aduciendo tres razones principales ${ }^{20}$. Añade también la posibilidad de que el texto sea enmendado, completado o ampliado con renovadas informaciones: «[...] rogándovos que antes que divulguedes o publiquedes este tractado lo queráis mostrar a algunas personas entendidas e que ayan leído semejables istorias, corrigiendo o emendándola $»^{21}$.

En definitiva, Villena no está interesado en las historias mitológicas como un fin en sí mismas, sino como artefactos literarios muy aptos para la enseñanza moral en el marco de una sociedad que se abría paso decididamente hacia una comprensión más amplia y completa del ser humano.

\section{ESTUDIO FILOLÓGICO DEL ESTILO EN LOS DOZE TRABAJOS DE HÉRCULES}

\subsection{Aspectos generales de la lengua literaria del Cuatrocientos}

Pese a que Villena no llega en esta primera obra de su producción literaria a la artificiosidad extremada que exhibe en su traducción de la Eneida ${ }^{22}$, lo cierto es que el texto de Los doze trabajos de Hércules atesora los rasgos más representativos que se observan en la prosa castellana cuatrocentista. Si por algo se identifica a la literatura creada en este siglo XV es por su imitación extrema de la lengua latina. La razón es de sobra conocida: al ostentar la lengua del Lacio la

${ }^{19}$ Sigue la disposición de Consolatio Philosophiae y de De disclipina Scholarium de Boecio.

${ }^{20}$ En la primera razón aduce falta de tiempo e imposibilidad de consultar su biblioteca. En una segunda razón alude al placer lector a la hora de intentar completar él mismo las interpretaciones implícitas, y en una tercera expresa el deseo de no restringir las variadas interpretaciones que pueden extraerse.

${ }^{21}$ Pedro M. Cátedra, Obras..., ed. cit., p. 111.

${ }^{22}$ Véase el estudio y edición de Ramón Santiago Lacuesta, La primera..., ed. cit., el trabajo de Pedro M. Cátedra, «El sentido involucrado y la poesía de siglo xv. Lecturas virgilianas de Santillana, con Villena», en Ana Menéndez Collera y Víctor Roncero López (eds.), Nunca fue pena mayor. Estudios de literatura española en homenaje a Brian Dutton, Cuenca, Ediciones de la Universidad de Castilla-La Mancha, 1996, pp. 149-162, así como el artículo de Juan Gil, «Los latinismos sintácticos...», art. cit. 
categoría indiscutible de modelo lingüístico de prestigio por ser el vehículo de comunicación cultural responsable de transmitir el legado de la Antigüedad clásica, era inevitable que los escritores del Cuatrocientos abrazaran de forma entusiasta y algo atropellada una forma literaria basada en la imitación de este modelo de prestigio.

Así, uno de los rasgos más frecuentes en el texto que nos ocupa radica en disponer el verbo al final de la oración, con la consiguiente alteración del orden natural de la sintaxis romance y el acercamiento a la estructura sintáctica del modelo latino: «Fasta aquí he puesto so brevedad la alegórica e moral significaçión de la tañida poesía, pero por que non entiendan los leyentes que sin real historia esto passase $\rangle^{23}$.

De forma complementaria a este rasgo, se registra un empleo profuso del hipérbaton, con el fin de dotar de mayor expresividad y exuberancia a la prosa. Se altera así el orden sintáctico en diferente grado, pues en los dos primeros ejemplos la dislocación no resulta tan violenta como en el tercer ejemplo, en el que se observa una deliberada modificación en la sintaxis:

Fue a mí plazible vuestra loadera inclinaçión e la satisfaçión cargosa, considerando mis insufiçiençia e discreçión, siquiera la poquedat de istorias por mí vistas, non algo menos las curiales e familiares ocupaçiones que non dan logar e, sobre todo, las adversidades de la movible fortuna non consintiendo el mío reposar pensamiento ${ }^{24}$.

Dentro del conjunto de rasgos caracterizadores de la lengua cuatrocentista, quizá el uso de latinismos gráficos constituya la mayor seña de identidad. Así, el empleo constante de los grupos consonánticos cultos - $\mathrm{CT}-,-\mathrm{GN}-,-\mathrm{PT}-,-\mathrm{PN}-\mathrm{O}-\mathrm{TH}-$, presente en voces como fructo, tractado, regno, corrupto, dapnificados o theológico, entre otros muchos, representa una muestra sobresaliente del entusiasmo de este conjunto de escritores por el componente latino en una forma tan visible como es la grafía ${ }^{25}$.

Otro rasgo que denota una imitación del modelo latino es el uso del participio de presente, que cabe entender como un resto sintáctico procedente del latín ${ }^{26}$ :

\footnotetext{
${ }^{23}$ Pedro M. Cátedra, Obras..., ed. cit., p. 93.

${ }^{24}$ Ibidem, p. 6.

${ }^{25}$ Con todo, en numerosas ocasiones se deslizan errores a la hora de introducir estas formas latinas, algo que Rafael Lapesa, Historia de la lengua española, Madrid, Gredos, 1981, p. 271, atribuye a los defectos de la transmisión oral en la enseñanza del latín en formas como inorar, cirimonia, absuluto, noturno o perfeción. También Rosa M. ${ }^{a}$ Lida de Malkiel, Juan de Mena..., op. cit., pp. 261-262, constata algunos ejemplos en este autor como inoto, repuna, costancia, eçelencia, inteleto, diçiones, eleto o esecrables.

${ }^{26}$ Afirma Rafael Lapesa, «Los casos latinos: restos sintácticos y sustitutos en español», en Rafael Cano Aguilar y M. ${ }^{\text {a }}$ Teresa Echenique Elizondo (eds.), Estudios de morfosintaxis histórica del español, Madrid, Gredos, 2000 [1964], p. 117: «Los escritores del siglo Xv, tan dados al latinismo, la emplean [la construcción absoluta del participio de presente] también en
} 
[...] poniendo en ella cómo desçendió el dicho Hércules a los infiernos en vida. E otros virtuosos actos que fizo, moviendo a virtud a los estonçes bivientes e a los que después vernién, compusieron. E será muy provechoso a los leyentes, acuçiando los valientes coraçones a semejables e grandes fechos ${ }^{27}$.

Como puede comprobarse, los dos casos aducidos de participio de presente funcionan como elementos sustantivados mediante el artículo correspondiente, pero, de acuerdo con Ridruejo ${ }^{28}$ y Gil ${ }^{29}$, esta forma desarrolló, ante todo, carácter adjetival («Por estado de mercader entiendo los comprantes e vendientes siquiera mareantes que por ganançias de fletes e pasadas por los mares fazen preçios») y verbal («Estonçes el virtuoso trava el mundo por los cuernos, vençiendo con razón las falsas impugnaçiones de los reprehendientes $\rangle^{30}$ ). Tal como sugiere Ridruejo ${ }^{31}$, este uso del participio de presente en Villena debe catalogarse como una construcción propia de los romances del Este peninsular, esto es, del catalán y del aragonés, en los que, como resultado de la identificación fónica entre esta forma y la propia de gerundio $^{32}$, se desarrolló su carácter verbal frente al resto de romances peninsulares. Si a ello se suma la circunstancia de que Villena autotraduce del original en catalán, es indudable que nuestro autor adoptó tal sintagma de los romances peninsulares mencionados.

\subsection{Aspectos singulares de la prosa villenesca}

Un primer aspecto innovador se basa en un empleo especial del participio de presente. Así, aparte de los usos descritos, Juan Gil ${ }^{33}$ describe un empleo transgresor para la norma culta del español, y que tiene como protagonista a nuestro autor: la habilitación del participio de presente como transitivo a imitación de los usos del latín y "quizá espoleado por el francés". Tal hazaña creativa tuvo continuidad en Santillana, en Gómez Manrique y en Juan de Mena, hasta llegar al siglo Xvi con Juan de Padilla.

Tal como indica Gil ${ }^{34}$, la lengua del Lacio disponía de un participio de futuro activo (formas perifrásticas en [ama]-tūrus 'el que ha de amar'), pero no de su correspondiente aspecto pasivo, que se

indicaciones modales o de circunstancia accesoria: "Fortuna non discrepante / a sabia Naturaleza / tales dos vuestro semblante / fabricaron sin pereça (Santillana, NBAE, XIX, 557a)"».

${ }^{27}$ Pedro M. Cátedra, Obras..., ed. cit., p. 7.

${ }^{28}$ Emilio Ridruejo Alonso, «Tres catalanismos...», art. cit., pp. 276-280.

${ }^{29}$ Juan Gil, «Latinismos sintácticos...», art. cit., p. 182.

${ }^{30}$ Ejemplos tomados de Emilio Ridruejo Alonso, «Tres catalanismos...», art. cit., p. 280.

${ }^{31}$ Ibidem, pp. 279-280.

${ }^{32}$ A estos romances habría que sumar las variedades dialectales del Norte de Italia, el francés y el occitano, tal como señala Emilio Ridruejo Alonso, «Tres catalanismos...», art. cit., p. 278.

${ }^{33}$ Juan Gil, «Latinismos sintácticos...», art. cit., pp. 182-188.

${ }^{34}$ Ibidem, p. 189. 
suplió con el llamado gerundivo (con desinencia [ama]-ndus 'el que ha de ser amado'). Pues bien, una de las innovaciones ${ }^{35}$ de don Enrique de Villena consistió en proveer a la lengua castellana de un equivalente formal que representara ambas formas de participio, y para ello recurrió a los adjetivos formados con el afijo -dero. Sin embargo, ambas formas de participio (las terminadas en -tūrus y en -ndus), ya en latín vulgar, acabaron por confundirse y asimilarse; confusión que heredó la desinencia mencionada para el castellano, por lo que el afijo derivativo - dero asumió también los valores de las formas en -tūrus ${ }^{36}$. Así, en la obra que nos ocupa, se registra el uso de ambos valores del participio de futuro: tanto del valor pasivo ( «furtos e rapiñas es cosa mucho apartadera [=repellenda] e guisada de redrar las çibdades») como del activo («los presentes e venideros $[=$ uenturi $]$ cavalleros que actual e moralmente buscan enxemplo») ${ }^{37}$. Pese a que la innovación no logró triunfar en toda su extensión, hay que reconocer en Villena su aportación valiosísima a la lengua literaria de su tiempo. En este sentido, $\mathrm{Gil}^{38}$ pondera esta intervención estilística en los términos siguientes:

En conclusión, pues, la mayoría de estas construcciones latinizantes nació muerta. Villena solo se sirvió de ellas para trasladar a Virgilio: un ejemplo más de cómo la obra traducida influye sobre el traductor. Pero dos de los usos que intentó fomentar con su autoridad y ejemplo pervivieron largos años. No es pequeño logro.

Pero no todos los rasgos se orientan a imitar el modelo latino de prestigio. También afloran ciertas características propias de la evolución morfosintáctica de las lenguas romances ${ }^{39}$. En este sentido, Ridruejo $^{40}$ atiende a dos rasgos morfosintácticos, con una presencia continuada en autores vinculados a los diferentes espacios lingüísticos y culturales de la Corona de Aragón, como es el caso de Juan Fernández de Heredia ${ }^{41}$, de Íñigo López de Mendoza o del Arcipreste

${ }^{35}$ Juan Gil, «Latinismos sintácticos...», art. cit., p. 192, valora esta innovación como «otro de los experimentos del marqués, quizá el más original e interesante de todos». Y sigue más adelante: «Nadie como Villena, sin embargo, se percató de las posibilidades que ofrecían estos adjetivos [los terminados en - dero] para suplir la falta de participio de futuro (activo y pasivo) en castellano».

${ }^{36}$ Juan Gil, «Latinismos sintácticos...», art. cit., pp. 200-201, registra en la Eneida una lista de adjetivos terminados en - dero con la función propia del participio de futuro activo. Algunos ejemplos son las formas alborozadero, caedero, casadero, contecedero, esparcidero o fallecedero.

${ }^{37}$ Ejemplos tomados de Juan Gil, «Latinismos sintácticos...», art. cit., pp. 208-209.

${ }^{38}$ Ibidem, p. 211.

${ }^{39}$ Para una revisión de los fenómenos morfosintácticos en la Romania, véase el volumen editado por Andreas Dufter y Elisabeth Stark, Manual of Romance Morphosyntax and Syntax, Berlin, De Gruyter, 2017.

${ }^{40}$ Emilio Ridruejo Alonso, «Tres catalanismos...», art. cit., p. 276.

${ }^{41}$ Especialmente en aquellas traducciones dependientes de un modelo textual catalán o condicionadas por la intervención de un copista oriundo de ese dominio lingüístico, como en el 
de Talavera. Un primer fenómeno se basa en el empleo de la locución conjuntiva de valor concesivo ya sea que y de su variante ya sea, como puede apreciarse en esta cita textual: «Muy honorable e virtuoso cavallero, ya sea por vulgada fama fuese informado de vuestras virtudes $[\ldots]\rangle^{42}$. De acuerdo con Ridruejo ${ }^{43}$, el uso de esta formación fraseológica en Villena resulta un calco procedente del catalán jatsia $q u e$, si bien con el aragonés como agente intermediario de esta transferencia. El segundo fenómeno, también propio del catalán y del aragonés, se basa en el empleo del futuro de indicativo en la expresión de la eventualidad, registrado profusamente en Villena, como en la cita textual siguiente: «E esto fue escripto de aqueste trabajo en las reales e duraderas istorias a loor de Ércules e exemplo de los otros que querrán en esto parar mientes $\rangle^{44}$.

Además de los rasgos descritos, hay que hacer referencia a una construcción gramatical muy interesante desde el punto de vista del contraste lingüístico ${ }^{45}$. Se trata de la forma de disponer dos adverbios en -mente: «Plantó en el medio la philosofía, la cual por el maestro que la mostrase fuese defendida despiertamente e disputativa, así que la ganase con e por proprio trabajo $\rangle^{46}$. Desde su origen, la lengua castellana fijó la manera de disponer estos elementos mediante dos opciones posibles: o bien conservando el afijo - mente en ambas formas, o bien reservándola solamente para el segundo elemento (despierta o disputativamente). En cambio, en catalán medieval la forma de disponer estos adverbios resultó ser justo la contraria: o bien manteniendo ambos morfemas, o bien manteniendo tan solo el primero (despertament o disputativa). Teniendo en cuenta, pues, que Villena realiza una autotraducción a la lengua castellana de su versión original en catalán, podríamos plantear dos hipótesis: o bien Villena calcó esta construcción en la versión castellana, o bien se podría pensar que este rasgo sintáctico había permeado fuertemente en los usos escritos cultos del castellano de la Corona de Aragón ${ }^{47}$.

Finalmente, tal como ya destacó en su día Morreale ${ }^{48}$, resulta un rasgo singular de la prosa villenesca el uso de dos preposiciones coordinadas por la conjunción de valor aditivo $e$; rasgo que no se

caso de Rams de flores o Libro de actoridades, el Eutropio o las Vidas semblantes de Plutarco.

${ }^{42}$ Pedro M. Cátedra, Obras ..., ed. cit., p. 5.

${ }^{43}$ Emilio Ridruejo Alonso, «Tres catalanismos...», art. cit., p. 284 y Emilio Ridruejo Alonso, «Sobre ya sea que como locución concesiva en castellano», Revista de historia de la lengua española, 2 (2007), p. 145.

${ }^{44}$ Pedro M. Cátedra, Obras..., ed. cit., p. 27.

${ }^{45}$ Consúltese el libro de Germà Colón, El español y el catalán, juntos y en contraste, Barcelona, Ariel, 1989.

${ }^{46}$ Pedro M. Cátedra, Obras..., ed. cit., p. 32.

${ }^{47}$ Véase Coloma Lleal Galcerán, El castellano del siglo XV en la Corona de Aragón. Zaragoza, Institución Fernando el Católico, 1997, así como el Diccionario del castellano del siglo XV en la Corona de Aragón (DiCCA-XV), consultable desde $<\mathrm{http}: / /$ ghcl.ub.edu/diccaxv/home/ index/myLanguage:es>.

${ }^{48}$ Margherita Morreale, Los doze trabajos..., ed. cit., p. LXXI. 
registra en otros escritores de la época, y que cabría pensar en la posibilidad de que se trate de otro de sus experimentos de estilo: «El quinto trabajo de Hércules fue cuando sacó el Çerbero, can del infierno, domándolo e atando, por e $a$ defendimiento de sus compañeros Theseo e Periteo, que con él eran ${ }^{49}$.

\subsection{Fraseología hispánica medieval y codificación: posibilidades de estudio}

De un tiempo a esta parte se viene considerando la necesidad de describir el origen, desarrollo y consolidación de las unidades fraseológicas a lo largo de la historia del español ${ }^{50}$. Se trata, en efecto, de una línea de investigación inscrita en el ámbito de la historia de la lengua, que pretende dar cuenta de la red compleja de procesos históricos de fijación formal y semántica que explican tanto la configuración gramatical como el funcionamiento textual de estas unidades en su diacronía ${ }^{51}$.

Pues bien, en el caso concreto de Los doze trabajos de Hércules, en una visión global se puede apreciar un uso muy frecuente de combinaciones locucionales de tipo prepositivo como las marcadas en cursiva en las citas textuales siguientes: «E allí quedando, así queda el tal león desollado a enxemplo de los atrevidos. Aqueste tal despojo a gloria de tal perlado debe ser recordado siempre $\rangle^{52} \mathrm{y}$ 《E después trasladólo él mesmo en lengua castellana, a suplicaçión de Johán

\footnotetext{
${ }^{49}$ Pedro M. Cátedra, Obras..., ed. cit., p. 37.

${ }^{50}$ Consúltense los trabajos de M. ${ }^{\text {a }}$ Teresa Echenique Elizondo, «Pautas para el estudio histórico de las unidades fraseológicas», en José Luis Girón Alconchel, Ramón Santiago Lacuesta y Eugenio de Bustos Gisbert (eds.), Homenaje a José Jesús de Bustos Tovar, Madrid, Editorial Complutense, 2003, pp. 545-560; M. a Teresa Echenique Elizondo, «Notas de sintaxis histórica en el marco del corpus de diacronía fraseológica del español (DIAFRAES)», en Elisabeth Stark, Roland Schmidt-Riese y Eva Stoll (eds.), Romanische Syntax im Wandel, Tübingen, Gunter Narr Verlag, 2008, pp. 387-397; M. ${ }^{\text {a } T e r e s a ~ E c h e n i q u e ~ E l i z o n d o, ~ « A l g u n a s ~ n o t a s ~ s o b r e ~}$ latín y romance en la fraseología hispánica medieval», en Roger Wright (ed.), Latin vulgaire - latin tardif VIII: Actes du VIII colloque international sur le latin vulgaire et tardif (Oxford, 6-9 de septiembre de 2006), Oxford, St. Catherine's College, 2008, pp. 540-547. Asimismo, el estudio pionero de Rafael Lapesa, «Alma y ánima en el Diccionario histórico de la lengua española: su fraseología», en Juan Ramón Lodares (ed.), Léxico e Historia, II. Diccionarios, Madrid, Istmo, 1992 [1980], pp. 79-86, constituye igualmente referencia fundamental e ineludible en el ámbito de estudio de la fraseología histórica.

${ }^{51}$ Algunos de los resultados de esta línea de investigación pueden verse en M. ${ }^{\mathrm{a}}$ Teresa Echenique Elizondo, M. ${ }^{a}$ José Martínez Alcalde, Juan P. Sánchez Méndez y Francisco P. Pla Colomer (eds.), Fraseología española: diacronía y codificación, Madrid, CSIC, Anejo 104 de

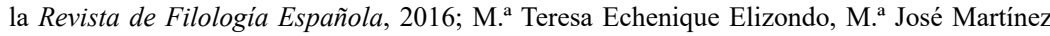
Alcalde (eds.) y Francisco P. Pla Colomer (coord.), La fraseología a través de la historia de la lengua española y su historiografía, Valencia/Neuchâtel, Tirant Humanidades/Université de Neuchâtel, 2017; M. ${ }^{\mathrm{a}}$ Teresa Echenique Elizondo, Angela Schrott y Francisco P. Pla Colomer (eds.), Cómo se "hacen" las unidades fraseológicas. Continuidad y renovación en la diacronía del espacio castellano, Berna, Peter Lang, 2018.

${ }^{52}$ Pedro M. Cátedra, Obras ..., ed. cit., p. 21.
} 
Fernández de Valera el moço, su escrivano en la su casa e notario público en todas las villas e logares de la su tierra» ${ }^{53}$.

Tal como puede apreciarse, el esquema $[\mathrm{P}+\mathrm{SN}+\mathrm{P}]$ resulta altamente representativo de este tipo específico de unidad fraseológica, si bien no resulta exclusivo. En este sentido, particularmente interesantes son las expansiones sintácticas de este esquema gramatical, basadas en la coordinación de dos elementos nominales. Tal como señala Lapesa ${ }^{54}$, la prosa cultivada en esta época «busca amplitud y magnificencia, desarrollando las ideas de manera reposada y profusa». En esa búsqueda de elegancia y ornamento expresivos, resulta, pues, un rasgo estilístico muy común en la lengua literaria del siglo $\mathrm{XV}$ el empleo de estas combinaciones fraseológicas formadas por dos sustantivos coordinados, con la consiguiente armonía y simetría en la arquitectura del discurso, como en la cita textual siguiente: «Esto fue escripto a loor e glorificacçión del grand Hércules, prestando castigo esa ora e al tiempo después a los atrevidos malfechores e doctrina a los que oy biven en cualquiera de los estados del mundo $[\ldots]\rangle^{55}$.

Por otra parte, es muy destacable la riqueza sinonímica en el uso de tales combinaciones locucionales, visible en series como las que siguen: por acresçentamiento de y a cresçimiento de, así como sus correspondientes variantes en cresçimiento de, por cresçimiento de y a pro e acresçentamiento de. El caso de las series sinonímicas a gloria de, a loor de y a loor e glorificacçión de, por un lado, y a duradera memoria de, a memoria e loor de, a perpetual memoria de, a memoria e recordaçión perpetua de, por recordança de, a remembrança de y en testimonio de, por otro, resulta especialmente significativo por su estrecha vinculación con la figura de Hércules.

En cuanto al estudio de la historicidad de estas unidades, se ha de tener presente que un gran número de estas locuciones consolida su uso en los primeros textos castellanos ${ }^{56}$, aunque pueda tenerse la percepción errónea de que sean relativamente recientes. En cambio, otras pueden ser producto de creación individual. Así, junto a unidades ya consolidadas en el uso literario de siglos anteriores, como

\footnotetext{
${ }^{53}$ Ibidem, p. 3.

${ }^{54}$ Rafael Lapesa, Historia de la lengua ..., op. cit., p. 269.

${ }^{55}$ Pedro M. Cátedra, Obras..., ed. cit., p. 84.

${ }^{56}$ Para un estudio de estas unidades, véase Santiago Vicente Llavata, Estudio de las locuciones en la obra literaria de don Ínigo López de Mendoza (Marqués de Santillana). Hacia una Fraseología histórica del español, Valencia, Universitat de València (Anejo 76 de Quaderns de Filologia), 2011; Viorica Codita Petrea, La conformación y el uso de las locuciones prepositivas en castellano medieval, Madrid/Frankfurt, Iberoamericana/Vervuert, 2016 y David Porcel Bueno, Variación y fijeza en la fraseología castellana medieval. Locuciones prepositivas complejas en la literatura sapiencial castellana (siglos XIII-XV), Tesis doctoral dirigida por M. ${ }^{a}$ Teresa Echenique Elizondo y Mariano de la Campa Gutiérrez, Valencia, Universitat de València, 2015.
} 
es el caso de so nombre de $e^{57}$ o por juizio $d e^{58}$, se registra un nutrido grupo de expresiones para las que el Corpus diacrónico del español no ofrece información, como a consejo e induzimiento de, a conservaçión e defendimiento de, a loor e glorificacçión de o a duradera memoria de, por lo que cabe pensar de nuevo en la innovación como posibilidad.

De forma complementaria a estos procedimientos metodológicos descritos, no podemos desatender uno de los cometidos fundamentales del binomio «fraseología hispánica medieval y codificación». En efecto, el estudio de las continuidades y discontinuidades estilísticas entre autores y corrientes literarias ${ }^{59}$ resulta una de las aplicaciones con mayor proyección en el estudio estilístico de la fraseología en su diacronía contrastiva.

En este sentido, otro filón prometedor en el estudio de la fraseología representada en Los doze trabajos de Hércules reside en considerar la huella estilística que dejó la Historia destructionis Troiae de Guido delle Colonne y sus respectivas versiones romances ${ }^{60}$ en esta obra. Y es que, tal como puede leerse en el estudio introductorio de Morreale ${ }^{61}$ : «Villena conocía esta importante obra [la Historia destructionis Troiae de Guido delle Colonne], que cita varias veces en el Tratado de consolación».

El alcance y trascendencia de ese estudio estilístico basado en la herencia de fraseología de materia troyana en Los doze trabajos de Hércules está todavía por comprobarse ${ }^{62}$. Se ofrecen por el momento,

${ }^{57}$ Real Academia Española: Banco de datos (CORDE) [en línea]. Corpus diacrónico del español. <http://www.rae.es> [Consulta: 19/10/2018]. Su primera documentación se corresponde con el Fuero Juzgo, 1250-1260: «De los que falso mandado lieuan, o falsas letras, so nombre de Rey o de juyz».

${ }^{58}$ Real Academia Española: Banco de datos (CORDE) [en línea]. Corpus diacrónico del español. <http://www.rae.es> [Consulta: 19/10/2018]. En el caso de por juizio de, su primera documentación se da en la General estoria: «E el que por gafo era judgado segund la vieja ley por juizio de su obispo».

${ }^{59}$ Para una aplicación a la obra literaria de Íñigo López de Mendoza, véase Santiago Vicente Llavata, op. cit.; Santiago Vicente Llavata, «Notas de Fraseología hispánica medieval. A propósito de la impronta catalano-aragonesa en la obra literaria de don Íñigo López de Mendoza», en Cesáreo Calvo Rigual y Emili Casanova Herrero (eds.), Actas del XXVI Congreso Internacional de Lingüistica y Filología Románicas, Berlín, DeGruyter, 2013, pp. 431-444; Santiago Vicente Llavata, «En torno a la voz quartonadas», Revista de Filología Románica, 34/2 (2017), pp. 211-228.

${ }^{60}$ El éxito formidable de la Historia destructionis Troiae de Guido delle Colonne (c. 1287) trajo consigo la aparición de multitud de versiones y reelaboraciones romances por toda Europa. Véase Juan Casas Rigall, La materia de Troya en las letras romances del siglo xiii hispano, Santiago, Servicio de Publicaciones de la Universidad de Santiago de Compostela, 1999 y el estudio introductorio de Ramón Lorenzo a su edición crítica de la Crónica troiana, La Coruña, Fundación Pedro Barrié de la Maza, 1985.

${ }^{61}$ Margherita Morreale, Los doze trabajos..., ed. cit., XIX, n. 1.

${ }^{62}$ Francisco P. Pla Colomer y Santiago Vicente Llavata, "Aproximación a una fraseología contrastiva en los textos peninsulares de materia troyana: el Libro de Alexandre, la Historia troyana polimétrica y la Crónica troyana de Juan Fernández de Heredia», en M. ${ }^{a}$ Teresa Eche-

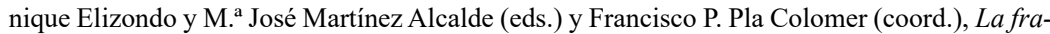
seología a través de la historia de la lengua española y su historiografia, Valencia/Neuchâtel, 
pues, algunos apuntes provisionales sobre estas herencias estilísticas en el uso de combinaciones locucionales en el texto villenesco, a la espera de sistematizar su estudio en un futuro trabajo.

Así, Menelao, afligido por el rapto de su esposa Helena, recibe el consejo de su hermano Agamenón, el cual le exhorta a que deponga esa actitud de debilidad y se vengue de tal ultraje infligido a su persona y a todo el pueblo de Grecia:

\begin{tabular}{|c|c|c|}
\hline $\begin{array}{l}\text { Historia destructionis } \\
\text { Troiae (c. 1287) }\end{array}$ & $\begin{array}{l}\text { La corónica troyana } \\
\text { (último cuarto } \mathrm{s} \text {. XIV) }\end{array}$ & $\begin{array}{l}\text { Libro de la } \\
\text { troyana }(1443)\end{array}$ \\
\hline $\begin{array}{l}{[\ldots] \text { Nosti enim nos }} \\
\text { habundare iuribus et in hac } \\
\text { ulciscendi cura nos multos } \\
\text { habere consortes, cum in } \\
\text { hoc tocius Grecie assurgat } \\
\text { imperium et a nobis moniti } \\
\text { reges singuli arma Troyanis } \\
\text { ingerere non negabunt. In } \\
\text { brachio fortissimo et multa } \\
\text { classe apud Troyam nos } \\
\text { vnanimiter conferemus } \\
{[\ldots]^{63} \text {. }}\end{array}$ & $\begin{array}{l}\text { [...] E non sera rrey njn } \\
\text { señor en toda Greçia que } \\
\text { nosotros rrequeramos que } \\
\text { denjegue ser en nuestra } \\
\text { conpañja e con buena } \\
\text { voluntad non sea con nos a } \\
\text { la tal vengança. E seremos } \\
\text { todos en vna voluntad e } \\
\text { con muy fuerte braço e } \\
\text { poderosamente e pujança } \\
\text { e de grand armada sobre }\end{array}$ & $\begin{array}{l}{[\ldots] . \text { Como en esta }} \\
\text { vengança todo el inperio } \\
\text { de Grecia se levante } \\
\mathrm{e} \text { a nuestra instancia } \\
\text { todos los reyes griegos } \\
\text { armas tomarán contra } \\
\text { los troyanos, e con muy } \\
\text { fuerte braço e muncha } \\
\text { abondança de fuerças } \\
\text { contra Troya de una } \\
\text { voluntad iremos }[. .]^{65} \text {. }\end{array}$ \\
\hline
\end{tabular}

Tabla 1. Resultados de traducción referidas al sintagma in brachio fortissimo.

Como puede apreciarse, ambas versiones castellanas traducen el sintagma prepositivo in brachio fortissimo con la expresión fraseológica con muy fuerte braço referida a la fortaleza y energía del ejército griego, con la finalidad de dar respuesta militar a las injurias recibidas por los troyanos.

Pues bien, lo realmente interesante es que Villena también recurre a este tipo de expresiones en su texto. Es evidente que, si se comparan los contenidos expuestos en relación con los pasajes del texto villenesco son, por fuerza, distintos, pero lo que importa destacar es que Villena tuvo entre los anaqueles de su nutrida biblioteca un ejemplar de la obra de Guido delle Colonne, y que la tuvo muy en cuenta

Tirant Humanidades/Université de Neuchâtel, 2017, pp. 113-153, así como Francisco P. Pla Colomer y Santiago Vicente Llavata, «Sobre fraseología y fraseometría históricas: la materia troyana en las tradiciones textuales medievales iberorromances», en M. ${ }^{\mathrm{a}}$ Teresa Echenique Elizondo, Angela Schrott y Francisco P. Pla Colomer (eds.), Cómo se "hacen” las unidades fraseológicas. Renovación y continuidad en la diacronía del espacio castellano, op. cit., pp. 29-54, trabajan en un proyecto común en el que se pretende caracterizar el estilo de los textos peninsulares de materia troyana desde la fraseología histórica contrastiva, a fin de determinar las dependencias entre los testimonios de esta tradición textual.

${ }^{63}$ Guido delle Colonne, Historia destructionis Troiae, Nathalie Edward Griffin (ed.), Cambridge, The Mediaeval Academy of America, 1936.

${ }^{64}$ Anónimo, La coronica troyana. A medieval Spanish translation of Guido de Colonna's Historia Destructionis Troiae, Frank Pelletier Norris (ed.), Chapell Hill, The University of North Carolina Press, 1970.

${ }^{65}$ Pedro de Chinchilla, Libro de la historia troyana, M. ${ }^{a}$ Dolores Peláez Benítez (ed.), Madrid, Editorial Complutense, 1999. 
para la redacción de sus propias obras, como es el caso del Tratado de consolaçión, y como puede ser el caso de la obra que nos ocupa.

Así, en el marco del tercer trabajo, en el que Hércules aleja a las arpías del rey Fineo en razón de su influencia perjudicial para con sus hijos, Villena hace uso del complejo prepositivo con mano de fortaleza para referirse a la actitud moral firme y perseverante de la persona virtuosa a la hora de controlar sus pasiones:

Aquesta ficçión en parte es parabólica e en parte fabulosa, significando por Fineo el estado del omne virtuoso, que debe seer rey de las sus passiones, rigiéndolas con mano de fortaleza e constançia moral. Aqueste tal conviene ser junto en matrimonio con la derecha entinçión e sana ${ }^{66}$.

En otro pasaje del texto, concretamente en el marco del sexto trabajo, en el que Hércules castiga la crueldad del rey Diomedes matándolo y entregando su cuerpo a los caballos como comida, Villena hace uso también de otra combinación fraseológica muy cercana a la anterior, con mano poderosa, con el fin de hacer referencia al modo guerrero con que afronta Hércules su misión en el reino de Tracia:

Non osaban decir en público sus quexas nin morar en el regno e menos salir d'él por la muchedumbre de las gentes que aquella diabólica más que humana fazían execuçión. El rumor e fama llegó a los fines de la tierra. D'esto sabidor Ércules, fue al regno de Trasçia con mano poderosa e subjudgó el rey Diomedes a si ${ }^{67}$.

Finalmente, en el décimo trabajo, en el que se cuenta la historia mitológica del robo del ganado de Hércules por parte de Caco, Villena hace uso de la combinación locucional de tipo adverbial con mano fuerte, con el fin de expresar la superioridad del héroe aqueo en su batalla particular contra el rey Gerión, que resulta el personaje supuestamente real que se esconde tras la fábula mitológica:

E tanta era la concordia e amistad entr'ellos, aviendo una voluntad, que fingieron que non era más de un Girión. E siquiere fuese uno, siquiere muchos, así como uno Hércules reduxo con mano fuerte a bien señorear e quitó los tuertos que por Girión antes en España eran fechos sin contradizimiento o detenimiento ${ }^{68}$.

A pesar de que no se dé una correspondencia formal idéntica entre todas las combinaciones fraseológicas consideradas, no será necesario insistir en la relación genética que se da entre las expresiones

\footnotetext{
${ }^{66}$ Pedro M. Cátedra, Obras ..., ed. cit., p. 24.

${ }^{67}$ Ibidem, p. 48.

${ }^{68}$ Ibidem, p. 81.
} 
con mano de fortaleza, con mano poderosa y con mano fuerte con respecto al sintagma in brachio fortissimo. El hecho de que nuestro autor utilice de forma frecuente estas expresiones tan próximas al modelo latino nos ha de hacer pensar en la posibilidad de que Villena estuviera lo suficientemente familiarizado con este texto historiográfico latino como para haber integrado en su estilo este tipo de locuciones. La constatación de esta última hipótesis implicaría revisar las fuentes indirectas de que se sirvió don Enrique de Villena a la hora de redactar su obra. Sirvan, pues, estas breves notas como antesala de un estudio estilístico de mayor alcance, en el que se deberá profundizar en la relación genética apuntada entre Los doze trabajos de Hércules y la tradición textual de materia troyana.

\section{CONSIDERACIONES FINALES}

Pertrechado con los más variados saberes, don Enrique de Aragón logró iluminar con su ciencia la senda en penumbra que asomaba a las puertas del prerrenacimiento hispánico en busca de nuevos ideales y de nuevas formas de entender la vida humana. Lapesa evoca este nuevo signo de los tiempos en estos bellos términos:

La antigüedad no es para los hombres del siglo XV simple materia de conocimiento, sino idea superior que admiran ciegamente y pretenden resucitar, mientras desdeñan la Edad Media en que viven todavía y que se les antoja bárbara en comparación con el mundo clásico. Alfonso $\mathrm{V}$ concierta una paz a cambio de un manuscrito de Tito Livio ${ }^{69}$.

Un rey que negocia una paz entre dos reinos a cambio de un manuscrito constituye una de las muestras más visibles y evidentes de ese nuevo tiempo denominado Humanismo. Este movimiento antropológico, cultural y artístico, que representa el afán de los hombres y mujeres del siglo XV por ennoblecer el vivir humano colectivo, se sumergió en el conocimiento de las enseñanzas morales de la Antigüedad clásica. Para don Enrique de Villena, la mitología no resulta, pues, una finalidad en sí misma, sino que, desde su firme creencia en la utilidad que presenta para la sociedad de su tiempo, la concibe como un poderoso instrumento ejemplarizante:

Con sus caballeros y príncipes, sus dictados (y en el texto de Villena sus crónicas), debían de parecer los antiguos extrañamente familiares a los lectores del siglo XV, y extraordinariamente actual su ejemplo. En su vestidura romance los clásicos tienen ya mucho del espíritu medieval y constituyen un puente entre uno y otro mundo ${ }^{70}$.

\footnotetext{
${ }^{69}$ Rafael Lapesa, Historia de la lengua..., op. cit., p. 267.

${ }^{70}$ Margherita Morreale, Los doze trabajos..., ed. cit., p. Xxxv.
} 
Desde el punto de vista de la expresión literaria, junto con el uso de ciertos rasgos comunes al castellano cuatrocentista (uso del hipérbaton y de latinismos gráficos, la posición final del verbo y el uso adjetival del participio de presente), hay que destacar su voluntad innovadora en el uso de formas inéditas en lengua castellana, como el empleo transitivo del participio de presente y de adjetivos con afijo - dero en calidad de elementos léxicos que reflejarían las formas de participio de futuro tanto activo como pasivo. Por otra parte, también en esta obra se dejan ver casos de transferencia morfosintáctica procedentes del catalán y del aragonés, como la posición excepcional de los adverbios terminados en -mente, el empleo de la locución conjuntiva de valor concesivo ya sea que o el uso del futuro de indicativo en la expresión de la eventualidad. Mención aparte merece el uso muy particular en la prosa villenesca de la doble preposición. En cuanto a posibles usos innovadores en los modos de expresión fraseológica, estamos todavía lejos de poder ofrecer alguna evidencia filológica, pues el estudio histórico de la fraseología representada en la obra literaria de don Enrique de Villena está todavía por acometerse, si bien se ha podido vislumbrar un intento de conectar diferentes tradiciones de textos a través de sus usos fraseológicos.

En definitiva, a pesar de que en el ámbito de la gestión política no logró encumbrarse hasta las cotas más altas de poder, el mérito sobresaliente de don Enrique de Villena hay que encontrarlo en su papel como líder intelectual tanto de su generación literaria como de las siguientes, donde hallaremos a figuras de relieve como Íñigo López de Mendoza, Juan de Mena o Gómez Manrique, en cuyas obras literarias permanecerá, rutilante e indeleble, la huella de su maestro. 
$\cos$

\section{HACIA UNA CARACTERIZACIÓN FILOLÓGICA DE LOS DOZE TRABAJOS DE HÉRCULES DE DON ENRIQUE DE VILLENA}

RESUMEN: Don Enrique de Aragón (c. 1384-1434) resulta una de las figuras más influyentes en el período del Humanismo peninsular. Su primera creación -Los doze trabajos de Hércules-constituye la primera interpretación mitológica del prerrenacimiento hispánico, al tiempo que constituye uno de los testimonios romances más antiguos del tópico de las armas y de las letras. Este artículo pretende caracterizar desde el punto de vista filológico sus rasgos de estilo más representativos, así como iniciar posibilidades renovadas de estudio, centradas en la Fraseología hispánica medieval.

PAlABRAS ClaVe: Humanismo peninsular, Corona de Aragón, prosa castellana del siglo XV, Fraseología histórica, Enrique de Villena.

TOWARDS A PHILOLOGICAL CHARACTERIZATION OF DON ENRIQUE DE VILLENA'S LOS DOZE TRABAJOS DE HÉRCULES

AbSTRACT: Don Enrique de Aragón (ca. 1384-1434) was one of the most influential figures of the period of the Peninsular Humanism. His first creation - Los doze trabajos de Hércules - constitutes the first mythological interpretation of the Spanish pre-Renaissance. In turn, it represents one of the oldest romances testimonies of the topic of arms and letters. This paper aims to characterize from the philological point of view their most representative style traits, as well as initiate renewed study possibilities, focused on Hispanic Medieval Phraseology.

Keywords: Peninsular Humanism, Crown of Aragon, Castilian prose of Fifteenth-Century, Historical Phraseology, Enrique de Villena. 